\title{
Orogastric tube insertion using the new gastric tube guide: first experiences from a manikin study
}

\author{
Christian Alflen $^{1^{*}}$ (D, Marc Kriege ${ }^{1}$, Irene Schmidtmann², Rüdiger R. Noppens ${ }^{3}$ and Tim Piepho ${ }^{1}$
}

\begin{abstract}
Background: Orogastric tube placement is a common procedure routinely used in clinical anesthesiology and intensive care medicine. Nevertheless high failure rates and severe complications have been reported. We conducted this study to evaluate if the usage of the new gastric tube guide would speed up the placement of orogastric tubes and ease the procedure.
\end{abstract}

Methods: Thirty one professionals were given a hands-on-training in orogastric tube placement in a simulation manikin without and with the gastric tube guide. Afterwards they performed both methods in randomized order. We recorded the placement time, counted the required attempts and asked the participants to rate their experience with both methods.

Results: The median placement time using the gastric tube guide was $14 \mathrm{~s}$ compared to $25 \mathrm{~s}$ without the device. In addition all participants were able to place the orogastric tube when using the gastric tube guide compared to 26/31 (84\%) without it. Furthermore 26/31 (84\%) users preferred the gastric tube guide over the standard method.

Conclusion: Our results show that using the gastric tube guide to place orogastric tubes in a manikin led to a significant shorter placement time and a higher overall success rate.

Keywords: Gastric tube guide, Orogastric tube, Nasogastric tube

\section{Background}

Insertion of an orogastric tube is a common procedure in clinical anesthesiology to achieve gastric decompression and to reduce gastric contents. The procedure is usually performed after induction of general anaesthesia and tracheal intubation. As the patient is unable to swallow and cannot follow further instructions placement of nasogastric and orogastric tubes can be difficult. This leads to a high failure rate of nearly $50 \%$ for the first attempt [1]. As the gastric tube will lose stiffness after warming to body temperature further attempts to place the tube will often result in subsequent failures [2]. Several methods to improve insertion of naso- and orogastric tubes have been published, including the use of

\footnotetext{
*Correspondence: chalflen@uni-mainz.de

Previous publication: Parts of this study have been presented at the German Congress of Anesthesiology 2016 in Leipzig Germany.

${ }^{1}$ Department of Anesthesiology, University Medical Center of the Johannes Gutenberg-University Mainz, Langenbeckstrasse 1, Mainz 55131, Germany Full list of author information is available at the end of the article
}

different forceps, various head positions, the use of a guidewire to increase the stiffness of the tube and recently the use of a slit endotracheal tube [3]. Further studies showed that the most common sites of resistance at the laryngeal level are the arytenoid cartilages and piriform sinuses [4]. Although the insertion of an orogastric tube is a common procedure several severe complications, like laryngeal injuries [5] and esophageal perforation [6], have been reported.

Based on the concept of slit endotracheal tubes the new gastric tube guide (VBM Medizintechnik GmbH, Sulz, Germany) was designed to facilitate the insertion of orogastric tubes. The device is made of polyvinyl chloride, is $33 \mathrm{~cm}$ in length, has an outer diameter of $10.3 \mathrm{~mm}$ and an inner diameter of $7.5 \mathrm{~mm}$ which allows the placement of gastric tubes up to $6.0 \mathrm{~mm}(18 \mathrm{Fr})$. According to the manufacturer the gastric tube guide is fitted with an insertion funnel on proximal end to ease the placement of gastric tubes and an atraumatic tip to 
decrease the risk of mucosal bleeding during the placement of orogastric tubes. It has a precurved shape (Fig. 1) to follow the anatomical structures of the pharynx and is equipped with graduation marks to adjust placement of the device. As slit endotracheal tubes the gastric tube guide has a slit shaft to allow the removal of the device without removing the orogastric tube.

The design of this study was made to investigate if the usage of the gastric tube guide leads to a higher success rate and a faster placement of orogastric tubes in a simulation manikin.

\section{Methods}

The Ethics committee of the medical association of Rhineland-Palatinate did not require a formal approval of the study. Thirty one professionals of the Department of Anesthesiology participated in this study, including fourteen nurses, ten residents and seven specialists. Each participant was given a hands-on demonstration for the placement of the orogastric tube with and without the gastric tube guide (Fig. 2). The participants had to use both methods in randomized order, randomization was performed using the Research Randomizer Software [7]. The simulation manikin ("Airway Management Trainer", Laerdal Medical GmbH, Puchheim, Germany) and gastric tube (14 Fr "Salem Sump PVC Gastroduodenal Tube", Covidien Deutschland GmbH, Neustadt/Donau, Germany) were the same for all participants and no further tools were allowed. We recorded the times required for successful gastric intubation and the number of attempts. Each complete removal of the tube from the manikin was counted as a new attempt. After the procedure the participant was asked to rate his or her overall experience with the tool ranging from 1 (best) to 6 (worst).

\section{Statistical analysis}

Descriptive analysis of the time to successful placement of the orogastric tube with each method was performed

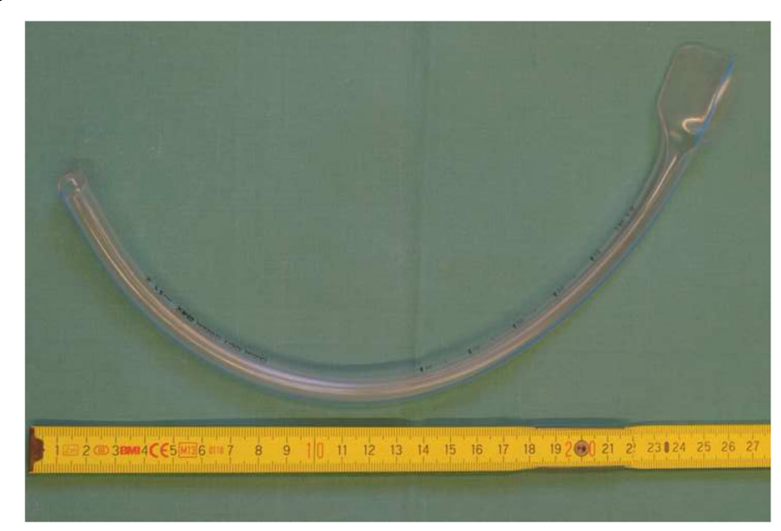

Fig. 1 Gastric tube guide - the gastric tube guide is $33 \mathrm{~cm}$ in length and has an inner diameter of $7.5 \mathrm{MM}$ using Kaplan-Meier estimates. Treatment effects and period effects were analyzed using Cox regression including a shared frailty term to take random participant effects into account. To describe the number of attempts and rating, absolute and relative frequencies are reported. The proportion of overall success are compared using the McNemar test, the preference and the number of attempts are evaluated using the Bowker test; $p$ values less than 0.05 were considered as significant.

Statistical analyses were performed using SAS 9.4 (2002-2012 SAS Institute Inc., Cary, NC, USA.)

\section{Results}

Twenty six participants (84\%) were able to place the orogastric tube within $180 \mathrm{~s}$ without using the gastric tube guide. All participants (100\%) were able to place the tube within $180 \mathrm{~s}$ when using the gastric tube guide $(p=0.0253)$. The median time required for orogastric intubation was 25 (95\% CI $[14 ; 65])$ seconds without and $14(95 \%$ CI $[11 ; 15])$ seconds with usage of the gastric tube guide, ranging from 4 to $123 \mathrm{~s}$ among those who successfully placed the gastric tube without the device and 6 to $20 \mathrm{~s}$ with the guide (Fig. 3). In the proportional hazard regression, we found no significant period effect $(\mathrm{HR}=0.72, p=0.2522$ for period $1 \mathrm{vs}$ period 2$)$ but a significant treatment effect ( $\mathrm{HR}=5.4, p<0.0001$ for gastric tube guide vs standard method). Table 1.

Of the participants, 22 (71\%) needed only one attempt to place the gastric tube without the device, five (16\%) made two attempts, four of which were successful and four $(13 \%)$ made three attempts - all without success. In contrast, 30 (97\%) of the participant were successful at the first attempt with the guide and only one participant (3\%) needed a second attempt to successfully place the gastric tube $(p=0.0293)$. All participants were able to remove the gastric tube guide without removing the orogastric tube. There was no malpositioning of the orogastric tube in the trachea in both groups. When rating the two methods, 26 (84\%) of the participants preferred the gastric tube guide to the standard method, whereas only one (3\%) preferred the standard method to the gastric tube guide and four (13\%) rated both methods in the same category $(p=0.0499)$. Table 2 .

\section{Discussion}

In our study we showed that using the gastric tube guide to place orogastric tubes leads to a higher success rate and a significantly shorter placement-time in manikins. In addition most users preferred the procedure when using the tool compared to the procedure without the gastric tube guide.

Usually gastric tubes will be placed using the oral cavity when they will be removed immediately after the procedure or before the patient recovers from anaesthesia. 

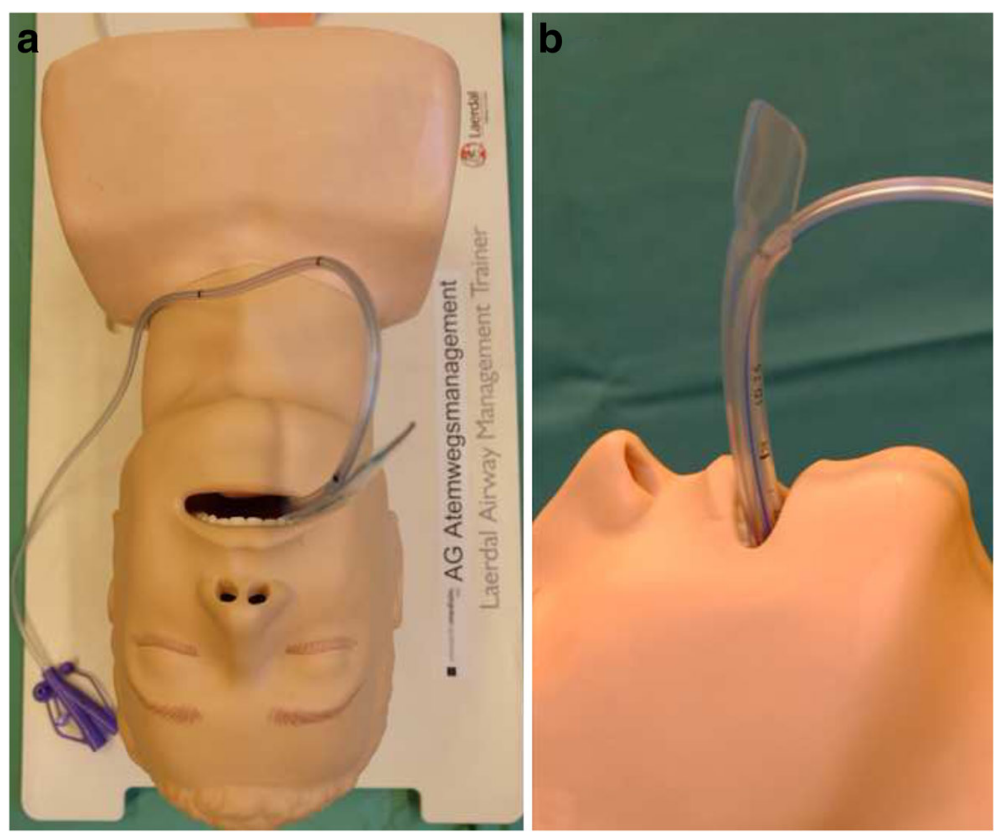

Fig. 2 Manikin with the gastric tube guide - (a) Experimental set-up with the manikin and an orogastric tube placed through a gastric tube guide; (b) Detail of the gastric tube guide with graduation marks (cm)

Compared to gastric tubes inserted through the nostril these techniques will most likely reduce complications like epistaxis, rhinitis and sinusitis. Other than that complications like laryngeal injuries, misplacement of the gastric tube and esophageal perforation might be the same for naso- and orogastric tubes [8]. As the placement of a gastric tube is a common procedure and has a high first-time failure rate various techniques have been described that should ease the procedure. Not considering laryngoscopy, these can be divided into two groups: the first group is characterized by movements of the head and neck to avoid the tip of the gastric tube to hit the common sites of resistance at the laryngeal level, e.g., applying lateral neck pressure or forced head flexion; the second group uses various methods to increase the stiffness of the gastric tube, e.g., freezing the tube or usage of a guide-wire [3]. A relatively new technique uses a slit endotracheal tube as a container to place the much softer gastric tube without the risk of kinking or knotting [9]. This procedure is similar to the placement of gastric tubes through supraglottic airway devices with a separate channel for esophageal access that have emerged during the last years [10]. After blind placement of the device a gastric tube can easily be placed through the second opening [11]. However, malpositioning of supraglottic airway devices is also known: Studies report incorrect positioning during in-hospital and prehospital conditions [12, 13].

The common sites of resistance for the tip of the gastric tube are the arytenoid cartilages and piriform

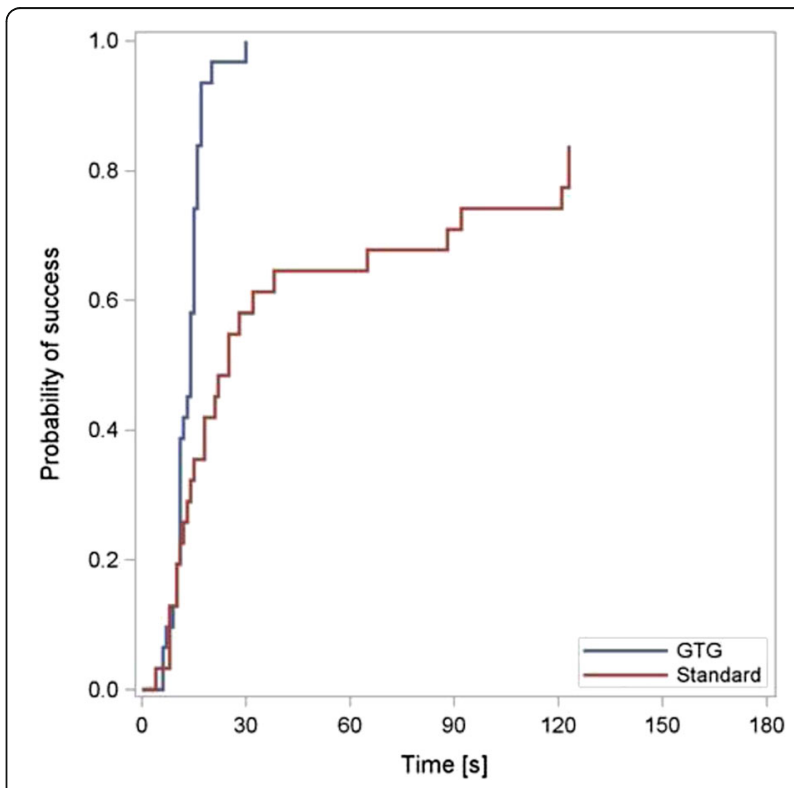

Fig. 3 Probability of success depending on the required time - All participants were able to place the gastric tube with the GTG, in contrast to 26 out of 31 without the device (standard). The median time required for successful orogastric intubation was 25 (95\% Cl $[14 ; 65])$ seconds without and $14(95 \% \mathrm{Cl}[11 ; 15])$ seconds with the $\mathrm{GTG}[\mathrm{HR}=5.4, p<0.0001]$ 
Table 1 Results

\begin{tabular}{|c|c|c|c|c|c|c|c|c|}
\hline \multirow[b]{2}{*}{ Participant } & \multirow[b]{2}{*}{ Training } & \multicolumn{3}{|c|}{ Standard - STD } & \multicolumn{3}{|l|}{ GTG } & \multirow[b]{2}{*}{ Sequence } \\
\hline & & Time [s] & Attempts [n] & Rating [1-6] & Time [s] & Attempts [n] & Rating [1-6] & \\
\hline 1 & Specialist & 38 & 1 & 4 & 16 & 1 & 2 & STD, GTG \\
\hline 2 & Specialist & 123 & 2 & 4 & 12 & 1 & 2 & STD, GTG \\
\hline 3 & Nurse & 22 & 1 & 3 & 16 & 1 & 1 & GTG, STD \\
\hline 4 & Nurse & fail & 3 & 6 & 20 & 1 & 2 & GTG, STD \\
\hline 5 & Nurse & 15 & 1 & 3 & 14 & 1 & 3 & STD, GTG \\
\hline 6 & Nurse & fail & 3 & 5 & 14 & 1 & 2 & STD, GTG \\
\hline 7 & Resident & 21 & 1 & 3 & 17 & 1 & 2 & GTG, STD \\
\hline 8 & Specialist & 123 & 2 & 4 & 15 & 1 & 2 & STD, GTG \\
\hline 9 & Resident & 25 & 1 & 3 & 15 & 1 & 1 & GTG, STD \\
\hline 10 & Resident & 28 & 1 & 3 & 17 & 1 & 1 & GTG, STD \\
\hline 11 & Resident & 88 & 1 & 4 & 15 & 1 & 1 & GTG, STD \\
\hline 12 & Resident & 10 & 1 & 2 & 7 & 1 & 1 & STD, GTG \\
\hline 13 & Resident & 14 & 1 & 2 & 11 & 1 & 1 & GTG, STD \\
\hline 14 & Nurse & 121 & 2 & 3 & 11 & 1 & 1 & STD, GTG \\
\hline 15 & Nurse & 25 & 1 & 3 & 14 & 1 & 1 & GTG, STD \\
\hline 16 & Nurse & fail & 3 & 5 & 15 & 2 & 2 & GTG, STD \\
\hline 17 & Specialist & 8 & 1 & 1 & 11 & 1 & 1 & STD, GTG \\
\hline 18 & Nurse & 11 & 1 & 3 & 11 & 1 & 3 & STD, GTG \\
\hline 19 & Specialist & 32 & 2 & 6 & 10 & 1 & 1 & STD, GTG \\
\hline 20 & Resident & fail & 3 & 6 & 17 & 1 & 1 & STD, GTG \\
\hline 21 & Specialist & 4 & 1 & 2 & 6 & 1 & 3 & GTG, STD \\
\hline 22 & Nurse & 65 & 1 & 3 & 14 & 1 & 1 & STD, GTG \\
\hline 23 & Nurse & 8 & 1 & 1 & 13 & 1 & 1 & GTG, STD \\
\hline 24 & Resident & fail & 2 & 5 & 30 & 1 & 1 & GTG, STD \\
\hline 25 & Nurse & 18 & 1 & 4 & 11 & 1 & 2 & STD, GTG \\
\hline 26 & Resident & 8 & 1 & 3 & 6 & 1 & 1 & STD, GTG \\
\hline 27 & Nurse & 10 & 1 & 2 & 10 & 1 & 1 & STD, GTG \\
\hline 28 & Nurse & 18 & 1 & 2 & 15 & 1 & 1 & GTG, STD \\
\hline 29 & Specialist & 13 & 1 & 4 & 9 & 1 & 2 & STD, GTG \\
\hline 30 & Nurse & 12 & 1 & 4 & 11 & 1 & 1 & STD, GTG \\
\hline 31 & Resident & 92 & 1 & 4 & 16 & 1 & 1 & GTG, STD \\
\hline
\end{tabular}

sinuses [4], as the gastric tube guide most likely will keep the gastric tube away from these sites this may be a reason for the faster placement of the orogastric tube when using the gastric tube guide. This may as well be due to the increased stiffness of the material used for

Table 2 Summary

\begin{tabular}{llll}
\hline & Standard & GTG & $p$ \\
\hline $\begin{array}{l}\text { Median placement } \\
\text { time and range (s) }\end{array}$ & $25[4-123]$ & $14[6-20]$ & $<0.0001$ \\
Overall success & $26 / 31(84 \%)$ & $31 / 31(100 \%)$ & 0.0253 \\
Prefered method & $1 / 31(3 \%)$ & $26 / 31(84 \%)$ & 0.0499 \\
\hline
\end{tabular}

the guide compared with typical orogastric tubes. A study using slit tracheal tubes for placement of gastric tubes showed an increased risk for mucosal bleeding during this procedure. They suggest using softer, round and thinner material for the guide than used for tracheal tubes [9], a requirement that is fulfilled by the gastric tube guide accordingly to the manufacturer.

It is recommended to insert a gastric tube under direct laryngoscopic vision in sedated or anaesthetised patients. This is especially true for high-risk patients who are on antiplatelet or antithrombotic medications as they have a greater likelihood of bleeding [5]. In addition, laryngoscopies may also result in injuries to the tongue and 
teeth. Furthermore, blood in the oropharynx can be the result of traumatic insertion of the gastric tube, particularly if the gastric tube was inserted without actively creating sufficient retropharyngeal space by means of a chin lift manoeuver or with a laryngoscope. After correct placement of the gastric tube guide as a container, a gastric tube, advanced through the device, should reach the stomach easily if there are no pathological findings. Another problem of inserting a gastric tube under direct or indirect laryngoscopy is the space in the oral cavity: The oral tube and the blade often do not allow placing the gastric tube - although the esophageal entrance is under direct or indirect vision.

Our findings showed a significant reduction of the time needed for successful orogastric intubation from 25 (95\% CI $[14 ; 65])$ seconds without to $14(95 \%$ CI $[11 ; 15])$ seconds with the gastric tube guide. Although the reduction of $11 \mathrm{~s}$ may not be relevant in clinical routine we suppose that this effect will be greater in the clinical setting as the placement time in general was short during our study. Another important finding was the reduction of attempts until an orogastric tube could be inserted when using the gastric tube guide as every attempt increases the risk of complications especially for mucosal bleeding and laryngeal injuries.

A limitation of our study may be the applied time limit of 180 s. This was done for two reasons: First, we wanted to reduce the effect of personal motivation on the attempts performed, especially on when to stop the procedure in case of several failed attempts. Second, as the placement of orogastric tubes can be time consuming we wanted a defined cut-off. Indeed no participant was able to place an orogastric tube after $123 \mathrm{~s}$ which might be due to reduced stiffness of the tube after warming up [2], so the time limit did not alter the results of the overall success rate.

Manikin studies in general have been proven to be a reliable surrogate for clinical scenarios. On one hand the setting cannot simulate the precise conditions in a real patient in this context especially the warming to body temperature and the presence of various body fluids, on the other hand the use of manikins allows a strict standardization of study conditions. For that reason further clinical studies are necessary to determine the benefits and risks when using the gastric tube guide to place orogastric tubes.

\section{Conclusion}

Our study showed that the usage of the gastric tube guide to place orogastric tubes in a simulation manikin leads to a higher success rate and a faster placement time and may therefore also be beneficial in clinical routine to reduce complications associated with the placement of orogastric tubes.
Abbreviations

Fr: French; GTG: Gastric tube guide

Funding

No funding was obtained for this study.

Availability of data and materials

All data generated or analysed during this study are included in this published article.

\section{Authors' contributions}

CA (corresponding author) designed the study, collected most of the data and wrote main parts of the manuscript, MK contributed to the design of the study and the manuscript, IS performed statistical analysis and wrote parts of the manuscript, RN made contributions to the design of the study, statistical analysis and the manuscript, TP made modifications to the design of the study, drafted the manuscript and wrote parts of it. All authors read and approved the final manuscript.

\section{Competing interests}

The authors declare that they have no competing interests.

Consent for publication

Not applicable.

\section{Ethics approval and consent to participate}

No patients or biological samples were included in this study. Ethics approval was therefore not required as told by the Ethics committee of the medical association of Rhineland-Palatinate with the reference number 837.384.14 (9623).

\section{Publisher's Note}

Springer Nature remains neutral with regard to jurisdictional claims in published maps and institutional affiliations.

\section{Author details}

${ }^{1}$ Department of Anesthesiology, University Medical Center of the Johannes Gutenberg-University Mainz, Langenbeckstrasse 1, Mainz 55131, Germany. ${ }^{2}$ Institute of Medical Biostatistics, Epidemiology, and Informatics, University Medical Center of the Johannes Gutenberg-University Mainz,

Langenbeckstrasse 1, Mainz 55131, Germany. ${ }^{3}$ Department of Anesthesia \& Perioperative Medicine, Western University, London, ON, Canada.

Received: 6 October 2016 Accepted: 20 March 2017

Published online: 04 April 2017

\section{References}

1. Bong CL, Macachor JD, Hwang NC. Insertion of the nasogastric tube made easy. Anesthesiology. 2004;101:266.

2. Boyes RJ, Kruse JA. Nasogastric and nasoenteric intubation. Crit Care Clin. 1992:8:865-78.

3. Appukutty J, Shroff PP. Nasogastric tube insertion using different techniques in anesthetized patients: a prospective, randomized study. Anesth Analg. 2009;109:832-5. doi:10.1213/ane.0b013e3181af5e1f.

4. Ozer S, Benumof JL. Oro- and nasogastric tube passage in intubated patients: fiberoptic description of where they go at the laryngeal level and how to make them enter the esophagus. Anesthesiology. 1999:91:137-43.

5. Burad J, Deoskar S, Bhakta P, Date R, Sharma P. Avoidance of Laryngeal Injuries during Gastric Intubation. Sultan Qaboos Univ Med J. 2014;14: e405-8.

6. Turabi AA, Urton RJ, Anton TM, Herrmann R, Kwiatkowski D. Esophageal perforation and pneumothorax after routine intraoperative orogastric tube placement. Case Rep. 2014;2:122-4. doi:10.1213/XAA.0000000000000019.

7. Urbaniak GC, Plous S. Research Randomizer (Version 4.0). 2013.

8. Prabhakaran S, Doraiswamy VA, Nagaraja V, Cipolla J, Ofurum U, Evans DC, et al. Nasoenteric tube complications. Scand J Surg. 2012;101:147-55.

9. Kwon OS, Cho GC, Jo CH, Cho YS. Endotracheal tube-assisted orogastric tube insertion in intubated patients in an ED. Am J Emerg Med. 2015:33: 177-80. doi:10.1016/j.ajem.2014.11.004. 
10. Hernandez MR, Klock PA, Ovassapian A. Evolution of the extraglottic airway: a review of its history, applications, and practical tips for success. Anesth Analg. 2012;114:349-68. doi:10.1213/ANE.0b013e31823b6748.

11. Verghese C, Ramaswamy B. LMA-Supreme-a new single-use LMA with gastric access: a report on its clinical efficacy. Br J Anaesth. 2008;101:405-10. doi:10.1093/bja/aen174.

12. Michalek P, Donaldson W, Vobrubova E, Hakl M. Complications associated with the use of supraglottic airway devices in perioperative medicine. BioMed Res Int. 2015;2015:746560. doi:10.1155/2015/746560.

13. Brimacombe J, Keller C. Aspiration of gastric contents during use of a ProSeal laryngeal mask airway secondary to unidentified foldover malposition. Anesth Analg. 2003;97:1192-4.

Submit your next manuscript to BioMed Central and we will help you at every step:

- We accept pre-submission inquiries

- Our selector tool helps you to find the most relevant journal

- We provide round the clock customer support

- Convenient online submission

- Thorough peer review

- Inclusion in PubMed and all major indexing services

- Maximum visibility for your research

Submit your manuscript at www.biomedcentral.com/submit
) Biomed Central 